\title{
PHYSICAL AND MECHANICAL PROPERTIES OF THE BAMBUSA VULGARIS AS CONSTRUCTION MATERIAL
}

\author{
José A. Gomes Neto ${ }^{1 *}$, Normando P. Barbosa ${ }^{1}$, \\ Antônio L. Beraldo², Aluísio B. de Melo
}

${ }^{1 *}$ Corresponding author. Federal University of Paraíba/ João Pessoa - PB, Brazil.

E-mail: jaugustogn@ @otmail.com | ORCID ID: https://orcid.org/0000-0003-2110-1882

\section{KEYWORDS}

bamboo, mechanical properties, physical properties, sustainable construction.

\begin{abstract}
The fabrication of traditional construction materials consumes a large amount of energy, emits pollutants, and utilizes nonrenewable raw materials. Therefore, it is important to reduce the environmental impact of construction through the use of eco-friendly materials, such as bamboo. This work presents the characterization of Bambusa vulgaris, which is widely available in Brazil. The aim is to employ this raw material as a construction material. The geometric and physical properties were obtained. The results showed that, when bamboo is soaked in water, dimensional variations up to $7 \%$ were observed along the radial direction. The mechanical properties depend on the moisture content. The compressive strength can exceed $60 \mathrm{MPa}$ with approximately $7 \%$ moisture content, while the tensile strength can exceed $100 \mathrm{MPa}$.
\end{abstract}

\section{INTRODUCTION}

The environmental problems that emerge from construction activities must be reduced. Several construction materials are produced at high temperatures, such as steel $\left(1700{ }^{\circ} \mathrm{C}\right)$, Portland cement $\left(1450{ }^{\circ} \mathrm{C}\right)$, and ceramic blocks (900-1000 ${ }^{\circ} \mathrm{C}$ ) (Mehta \& Monteiro, 2014), and generate large amounts of pollutants and waste. The use of renewable materials is essential to diminish the exploitation rate of mineral resources. Bamboo has potential applications in construction, contributing to sustainable architecture (Figure 1). Among its advantages are that it is renewable, uses solar energy for growth, absorbs $\mathrm{CO}_{2}$ instead of releasing it to the atmosphere, and grows faster than wood. Its physicomechanical properties are appropriate for engineering applications and, at the end of its cycle life, bamboo can be reintegrated into the environment. The sustainability of bamboo was emphasized by Zea Escamilla et al. (2016) and Escamilla et al. (2018). It has been shown that bamboo-based construction has no environmental impact in terms of $\mathrm{CO}_{2}$ emissions. The applications of bamboo as a building material are increasing, as seen in the work of Ghavami \& García (2017). The use of laminated bamboo in industry has also been investigated, as in Takeuchi et al. (2018).
In the tropics, there are approximately 75 genera and more than 1250 bamboo species, ranging from small grasses measuring a few centimeters to giant species over $40 \mathrm{~m}$ height and $30 \mathrm{~cm}$ in diameter (Liese \& Kohl, 2015).

Some characterization studies on bamboo species have been reported in the literature, such as those by Jakovljević \& Lisjak (2019), Espitia et al. (2018), Song et al. (2017), Bhonde et al. (2014), Xu et al. (2014), and Awalluddin et al. (2017). However, there are few studies on the properties of Bambusa vulgaris (B. vulgaris). In Brazil, the most widely used species in construction are Guadua angustifolia, Phyllostachys pubescens, Dendrocalamus asper, Bambusa tuldoides, and Phyllostachys aurea. Ghavami \& Marinho (2003) studied the properties of several bamboo species in Brazil, excluding B. vulgaris. As this species is the most widespread in the Brazilian northeast (there are over 5000 ha from an ancient paper industry in Paraiba State), the "Design of Bamboo Structures" standard is being prepared, making it necessary to obtain more information about the properties of this material. The bamboo culms used in the research were collected from a native forest close to the research center; the estimated age was four years.

${ }^{1}$ Universidade Federal da Paraíba/ João Pessoa - PB, Brasil.

${ }^{2}$ Universidade Estadual de Campinas/ Campinas - SP, Brasil.

Area Editor: André Luis Christoforo

Received in: 7-16-2020

Accepted in: 12-23-2020 
In general, the data from the literature cannot be compared with precision because various authors use different specimens to evaluate certain bamboo properties. In 2004, the International Organization for Standardization published the first technical standard for testing procedures to obtain the physical and mechanical properties of bamboo. However, tests have been conducted using different procedures. In addition, the mechanical properties of the material are dependent on its moisture content (MC). Thus, the desired precision of values reported in the literature is yet to be achieved. As a natural material, the mechanical properties of bamboo are highly variable. The variation coefficients can range from less than $20 \%$ to $40 \%$; however, this does not prevent the use of bamboo in buildings. In fact, recently developed bamboo standards consider the effects of humidity on bamboo and the variations in strength by considering characteristic values.
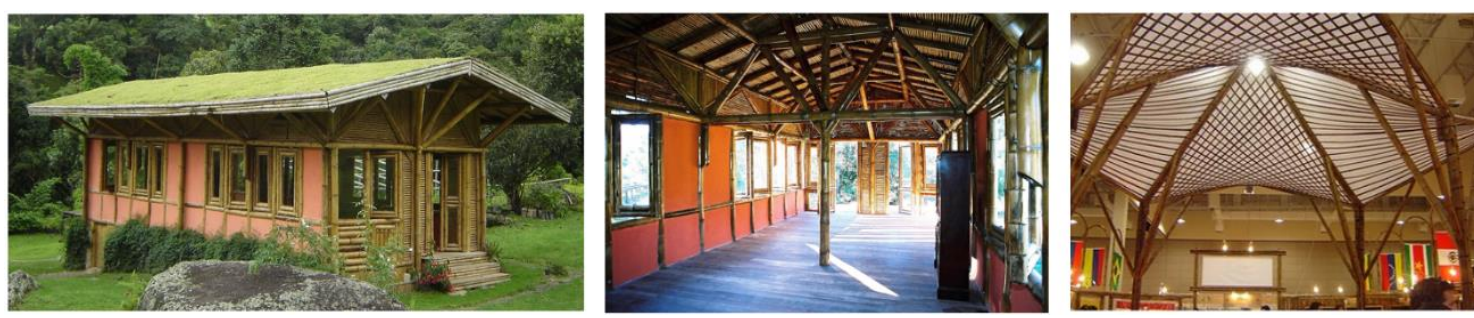

FIGURE 1. Environment-friendly bamboo constructions.

Source: Celina Llerena

\section{MATERIAL AND METHODS}

Physical and mechanical tests were performed according to "ISO 22157-1 (ISO, 2004) - Bamboo Determination of physical and mechanical properties - Part 1: Requirements," except for the shear strength parallel to the fibers.

\section{Geometric properties}

To make the study statistically significant, a minimum of six repetitions were performed, in which six mature bamboo culms were removed from different clumps. The useful length was divided into three parts: bottom, middle, and top. The properties evaluated were obtained from the average of six culms.

\section{Internode length}

The internode length along the height measured using a metallic ruler at the poles was approximately 30 internodes in their useful length.

\section{External diameter}

As the cross-section of the bamboo is not circular, at least four measurements were made at the center of each internode using a digital pachymeter with a sensitivity of $0.01 \mathrm{~mm}$.

\section{Wall thickness}

Each region (bottom, middle, and top) was divided into five parts, and the wall thickness of each part was measured three times. All measurements were made using a digital pachymeter with a sensitivity of $0.01 \mathrm{~mm}$.

\section{Physical properties}

The physical properties of the culms were obtained using the specimen shown in Figure 2. From each culm, nine samples were collected (three from the bottom, three from middle, and three from the top) for a total of 54 specimens.

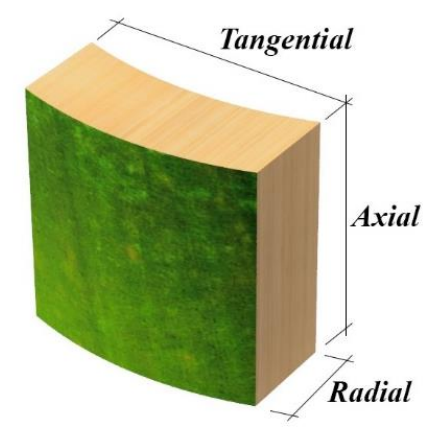

FIGURE 2. Specimen used.

\section{Natural moisture content}

The mechanical properties of bamboo are influenced by its MC, which is an important parameter in bamboo construction.

The natural MC (NMC) was measured after the mass of the specimen was stabilized at the laboratory. The specimens were weighed (M) and then placed in an oven at $103{ }^{\circ} \mathrm{C}$ for $24 \mathrm{~h}$, and weighed once again $\left(\mathrm{M}_{\mathrm{o}}\right)$. Equation 1 was employed to determine the NMC.

$$
N M C=\left(\frac{M-M_{o}}{M_{o}}\right) \times 100
$$

Where:

$$
\begin{aligned}
& \boldsymbol{N} \boldsymbol{M C}=\text { natural moisture content }(\%) ; \\
& \boldsymbol{M}=\text { Mass of the test piece before drying }(\mathrm{g}), \\
& \boldsymbol{M}_{\mathbf{0}}=\text { Mass of the same test piece after drying }(\mathrm{g})
\end{aligned}
$$

\section{Specific weight}

To determine the specific weight of each specimen and identify whether they have an irregular shape, a test to estimate the volume was performed following Archimedes' principle. A sensitivity balance of $0.01 \mathrm{~g}$ was used, and the specific weight was determined using [eq. (2)]. 


$$
\gamma=\frac{P_{s}}{V}
$$

Where:

$$
\begin{aligned}
& \boldsymbol{\gamma}=\text { Specific weight }\left(\mathrm{kN} / \mathrm{m}^{3}\right) \\
& \boldsymbol{P}_{\boldsymbol{S}}=\text { Dry sample weight }(\mathrm{kN}), \\
& V=\text { Volume }\left(\mathrm{m}^{3}\right)
\end{aligned}
$$

\section{Dimensional variation: shrinkage}

The dimensions of the specimens in three directions (axial, tangential, and radial) were measured under the saturated condition using a digital caliper of $0.01 \mathrm{~mm}$. Then, the specimens were exposed to a laboratory environment until they reached a stable weight, and the dimensions were measured again. The variation of dimensions divided by the initial values provides insights into bamboo shrinkage from the saturation to equilibrium MC, as expressed by [eq. (3)].

$$
\varepsilon=\frac{L_{i}-L_{f}}{L_{i}} \times 100
$$

Where:

$$
\begin{aligned}
& \boldsymbol{\varepsilon}=\text { Dimensional variation }(\%) ; \\
& \boldsymbol{L}_{\boldsymbol{i}}=\text { Initial reading }(\mathrm{cm}), \\
& \boldsymbol{L}_{\boldsymbol{f}}=\text { Final reading }(\mathrm{cm})
\end{aligned}
$$

\section{Dimensional variation: swelling}

The specimens were naturally dried in the laboratory environment in January, the hottest month of the year in the Brazilian northeast. The dimensions (axial, tangential, and radial) were measured using a digital caliper; the specimens were then immersed in water. The three dimensions were measured every day until the last two measurements became the same. The final swelling was obtained by [eq. (3)].

\section{Mechanical properties}

\section{Compressive strength parallel to the fibers}

Compressive strength parallel to the fibers was conducted on cylindrical specimens extracted from the culm, with a height and external diameter ratio of 1 , as recommended by ISO 22157-1 (ISO, 2004). A total of 108 specimens were tested with an MC of approximately $7 \%$ owing to the controlled laboratory environment. The specimens were obtained by cutting using a circular saw and smoothening of the surface using a disc sander to ensure appropriate contact with the CONTENCO I-3058 $100 \mathrm{tf}$ universal testing machine. The test speed was $0.5 \mathrm{MPa} / \mathrm{s}$. The compressive strength parallel to the fibers is expressed by [eq. (4)].

$$
\sigma=\frac{F}{A}
$$

Where:

$$
\begin{aligned}
& \boldsymbol{F}=\text { Higher load registered by machine }, \\
& \boldsymbol{A}=\text { Cross-sectional area }
\end{aligned}
$$

Tensile strength parallel to the fibers

Figure 3 shows a specimen for the tensile strength test. A total of 108 specimens were produced. Each bamboo culm was divided into three regions. From each region, six specimens were obtained, three with nodes and three without nodes. The specimens were tested using a SHIMADZU AG-X $10 \mathrm{kN}$ universal testing machine at a test speed of $2 \mathrm{~mm} / \mathrm{min}$.

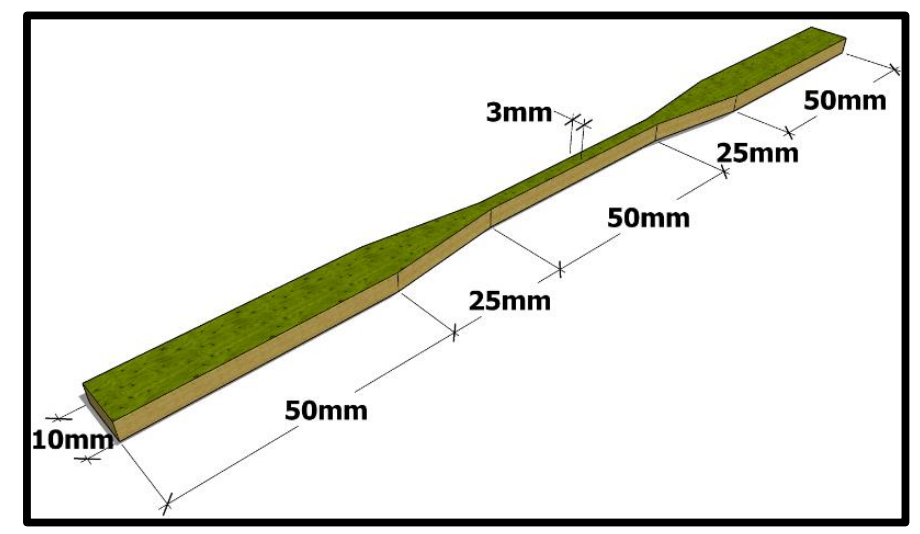

FIGURE 3. Specimens for testing tensile strength parallel to the fibers.

\section{Interlaminar shear strength parallel to the fibers}

To obtain the interlaminar shear strength parallel to the fibers, the test specimen proposed by Ghavami in the 1990s (Ghavami \& Barbosa, 2017) was used. A total of 108 specimens were tested at a speed of $2 \mathrm{~mm} / \mathrm{min}$. Figure 4 shows the dimensions of the specimens. 

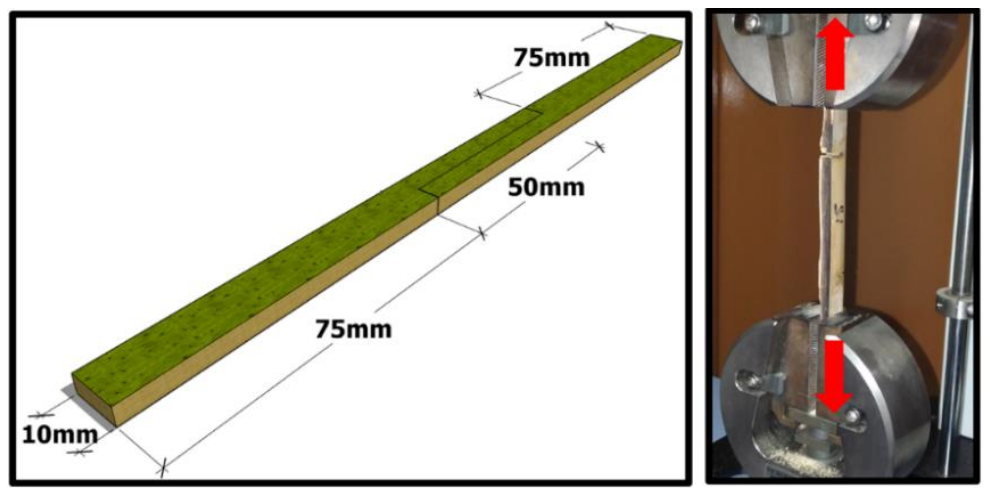

FIGURE 4. Specimens for testing interlaminar shear strength parallel to the fibers.

\section{RESULTS AND DISCUSSION}

\section{Geometric properties}

\section{Internode length}

Figure 5 shows the results of the internodal length measured in six culms of $B$. vulgaris. These measurements were made on 30 internodes separated by the culm region and with the minimum, average, and maximum length measurements.

Approximately $90 \%$ of the average dimensions ranged between $30 \mathrm{~cm}$ and $40 \mathrm{~cm}$. The base region had shorter internodes, while the center and top regions showed slightly homogeneous internode dimensions.

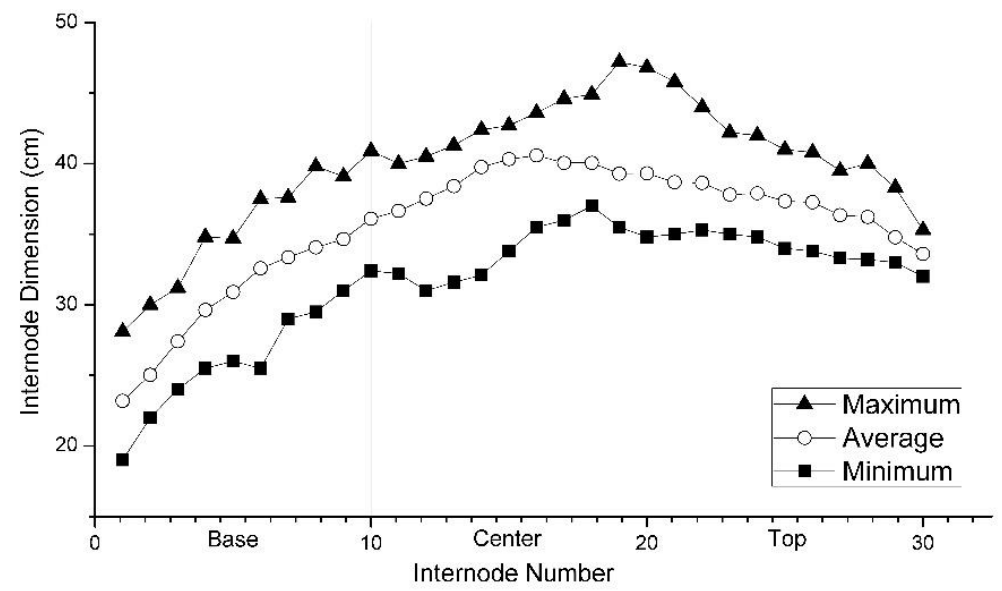

FIGURE 5. Result of the internodal dimension test.

Bhonde et al. (2014) showed a similar curve for Dendrocalmus strictus, and the same phenomenon was observed at the center of the internode. However, at the top, the internode length decreased more quickly compared with B. vulgaris.

Based on the results obtained, Ghavami (2005) reported similar curves for other bamboo species.

\section{External diameter}

Figure 6 presents the results of measuring the external diameter of the six bamboo culms. The curve is quite horizontal, with a slight drop in the apical region where the external diameter tends to be smaller. This characteristic is different from most species, where the external diameter decreases from the base to the top, as shown in Figure 7 (Ghavami \& Barbosa, 2017).

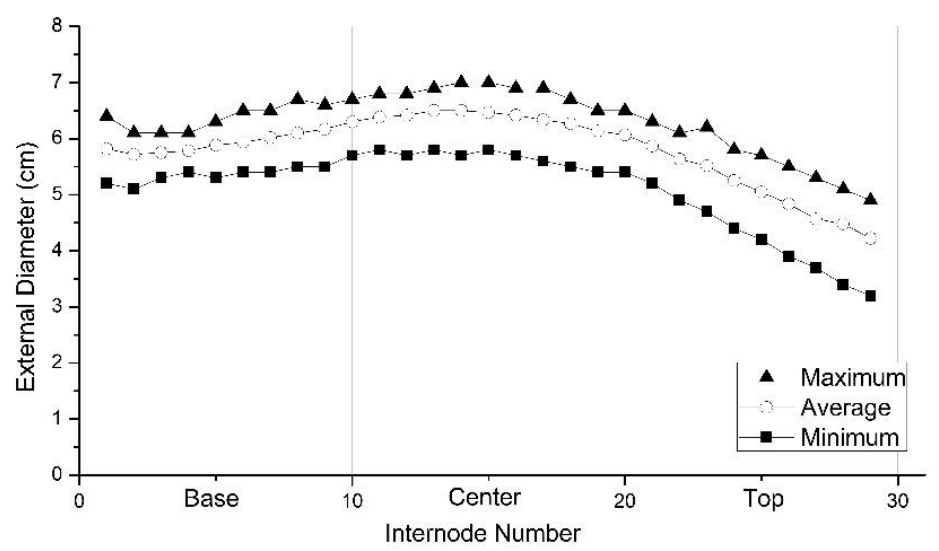

FIGURE 6. Variation of external diameter of B. vulgaris along the culm length. 


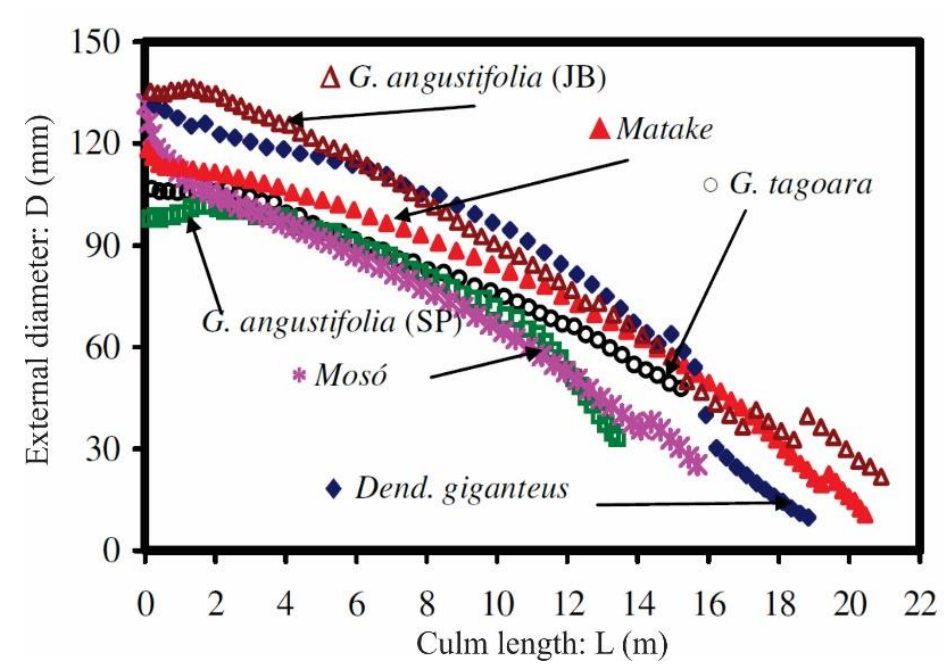

FIGURE 7. Adapted from Ghavami \& Barbosa (2017).

\section{Wall thickness}

Figure 8 shows the results obtained by measuring the wall thickness of $B$. vulgaris culms. There was a significant difference from the base to the top regions, with the thickness at the top considerably smaller than that at the base. This was observed for other bamboo species by Ghavami (2005).

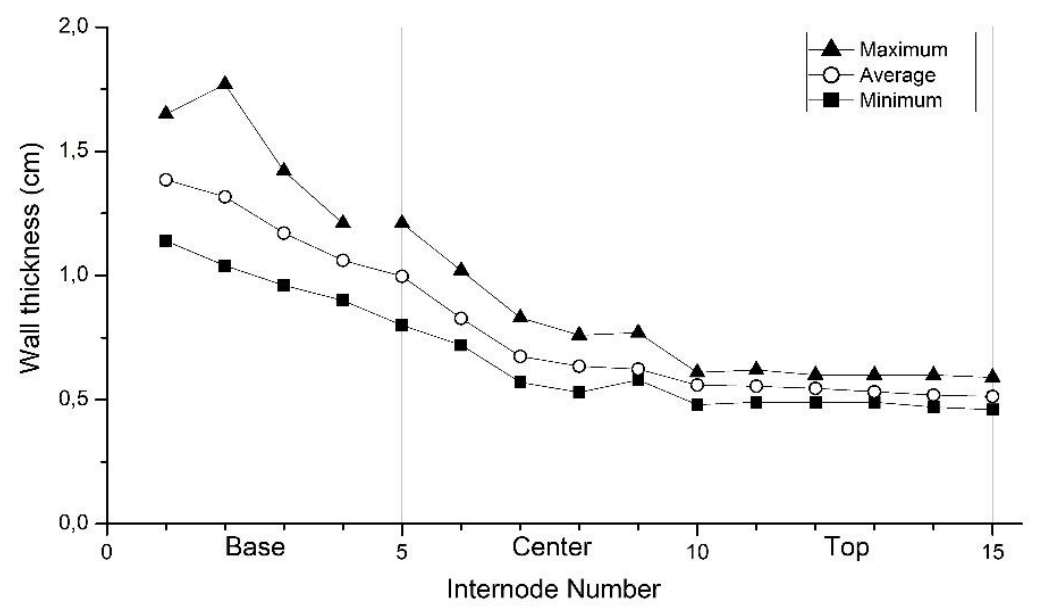

FIGURE 8. Wall thickness culm of B. vulgaris.

\section{Physical properties}

\section{Natural moisture content}

Table 1 lists the NMC of the bamboo culms, with average values of approximately $12 \%$. The $\mathrm{MC}$ of the specimens stabilized after seven to eight days at room temperature in the summer season. However, the NMC varied over time. In the rainy season, the MC of the poles can reach $15 \%$ in the northeastern region of Brazil. In general, the NMC content ranged between $10 \%$ and $16 \%$, based on the relative humidity and average temperature.

TABLE 1. Natural moisture content.

\begin{tabular}{lc}
\hline \multicolumn{2}{c}{ Moisture content $\mathbf{( \% )}$} \\
\hline Base & 12.48 \\
Center & 12.61 \\
Top & 11.53 \\
Average & 12.21 \\
Standard deviation (\%) & 0.59 \\
Variation coefficient $(\%)$ & 4.85 \\
\hline
\end{tabular}

\section{Specific weight}

The average specific weight of bamboo, in natural conditions, is $8.52 \mathrm{kN} / \mathrm{m}^{3}$. Bhonde et al. (2014) reported a specific weight of $7.83 \mathrm{kN} / \mathrm{m}^{3}$ for Dendrocalamus strictus. Carbonari et al. (2017) reported specific weights between $7.35 \mathrm{kN} / \mathrm{m}^{3}$ and $8.23 \mathrm{kN} / \mathrm{m}^{3}$ for four bamboo species. The highest value was obtained for Bambusa Oldhamii.

TABLE 2. Specific weight of B. vulgaris.

\begin{tabular}{lc}
\hline \multicolumn{2}{c}{ Specific weight $\left(\mathbf{k N} / \mathbf{m}^{\mathbf{3}}\right)$} \\
\hline Base & 8.83 \\
Center & 8.46 \\
Top & 8.28 \\
Average & 8.52 \\
Standard deviation & 1.06 \\
Variation coefficient $(\boldsymbol{\%})$ & 12.43 \\
\hline
\end{tabular}




\section{Dimensional variation: Shrinkage}

Bamboo shrinkage from saturation to equilibrium MC conditions is described in Table 3. In the axial direction, parallel to the fibers, shrinkage is negligible. In the other directions, both perpendicular to the fibers, shrinkage can reach 4-5\% owing to the internal structure of bamboo. When the bamboo wall loses water, it is easier for the lignin matrix to change dimensions in the direction perpendicular to the fibers.

TABLE 3. Shrinkage of bamboo from saturation to natural conditions.

\begin{tabular}{|c|c|c|c|}
\hline \multicolumn{4}{|c|}{ Dimensional Variation - Shrinkage (\%) } \\
\hline & Radial & Axial & Tangential \\
\hline Base & 4.49 & 0.22 & 4.69 \\
\hline Center & 5.06 & 0.39 & 3.98 \\
\hline Top & 5.55 & 0.29 & 3.50 \\
\hline Average (\%) & 5.03 & 0.30 & 4.06 \\
\hline Standard deviation (\%) & 0.53 & 0.09 & 0.60 \\
\hline Variation coefficient $(\%)$ & 10.54 & 28.27 & 14.67 \\
\hline
\end{tabular}

\section{Dimensional variation: Swelling}

As observed from the shrinkage presented in Table 3 , in the direction parallel to the fibers (axial), the increase in swelling was negligible and was the smallest at less than $0.5 \%$. The dimensional variations after saturation are listed in Table 4.

TABLE 4. Swelling of bamboo from environment to saturation.

\begin{tabular}{lccc}
\hline \multicolumn{4}{c}{ Dimensional Variation - Swelling (\%) } \\
\hline & Radial & Axial & Tangential \\
Base & 6.42 & 0.45 & 5.70 \\
Center & 7.28 & 0.49 & 4.76 \\
Top & 7.79 & 0.31 & 4.21 \\
Average (\%) & 7.17 & 0.42 & 4.89 \\
Standard deviation (\%) & 2.25 & 0.15 & 1.38 \\
Variation coefficient (\%) & 31.33 & 35.71 & 28.13 \\
\hline
\end{tabular}

\section{Mechanical properties}

\section{Compressive strength parallel to the fibers}

Bamboo compression strength is a property that is highly sensitive to MC. Xu et al. (2014) evaluated the compressive strength of Phyllostachys pubescens at $30 \%$ MC. They reported that, in this condition, the culms were only $75 \%$ compared with those evaluated at $12 \% \mathrm{MC}$.

Table 5 presents the results obtained in this study. As expected, when a node is located at the center of the specimen, the compressive strength is lower. The average compressive strength was $63.7 \mathrm{MPa}$, with a standard deviation and variation coefficient of $17.8 \mathrm{MPa}$ and $28.0 \%$, respectively. The MC of the specimens is presented in the third column of the table. At the nodes, the bamboo fibers undergo deviations that decrease the relative MC percentage of fibers in that location, thereby decreasing the strength. In the specimen with a node, it is difficult to predict the compression strength because the nodes are unequal. The fibers are parallel to the node, which causes local perturbation in the stress way. Meanwhile, in the specimen without a node, the relative percentage of fiber at the top is high. As fibers are the most resistant component of bamboo, their strength is also high.

Awalluddin et al. (2017) found that, for B. vulgaris from Malaysia, the compressive strength parallel to the fibers of specimens without a node ranged from 66.4 $\mathrm{MPa}$ (19\% MC) to $78.7 \mathrm{MPa}(14 \% \mathrm{MC})$.

TABLE 5. Results of the compressive strength parallel to the fibers.

\begin{tabular}{cccc}
\hline \multicolumn{4}{c}{ Compressive strength parallel to the fibers } \\
\hline Culm part & $\begin{array}{c}\text { With } \\
\text { node } \\
(\mathbf{M P a})\end{array}$ & $\begin{array}{c}\text { Without } \\
\text { node } \\
\text { (MPa) }\end{array}$ & $\begin{array}{c}\text { Moisture } \\
\text { content } \\
(\%)\end{array}$ \\
\hline Base & 43.16 & 64.72 & 7.13 \\
Center & 56.21 & 84.39 & 7.52 \\
Top & 48.63 & 85.00 & 6.94 \\
$\begin{array}{c}\text { Average } \\
\text { Standard } \\
\text { deviation }\end{array}$ & 49.33 & 78.04 & 7.19 \\
$\begin{array}{l}\text { Variation } \\
\text { coefficient }(\%)\end{array}$ & 38.62 & 32.05 & 2.16 \\
\hline
\end{tabular}

\section{Tensile strength parallel to the fibers}

Table 6 lists the tensile strength parallel to the fibers of specimens with and without nodes. The tensile strength was found to be lower in specimens with a node. The direction of the fibers changed sharply at the node region. Some of the fibers were interrupted when the specimen was prepared, which decreased the tensile strength.

Awalluddin et al. (2017) reported that, for $B$. vulgaris from Malaysia, the tensile strength of specimens without a node was higher than $200 \mathrm{MPa}$. However, the MC and age of the specimens were not reported, both of which influence the behavior of bamboo.

TABLE 6. Tensile strength parallel to the fibers of $B$. vulgaris.

\begin{tabular}{cccc}
\hline \multicolumn{4}{c}{ Tensile strength parallel to the fibers } \\
\hline Culm part & $\begin{array}{c}\text { With node } \\
\text { (MPa) }\end{array}$ & $\begin{array}{c}\text { Without } \\
\text { node (MPa) }\end{array}$ & $\begin{array}{c}\text { Moisture } \\
\text { content (\%) }\end{array}$ \\
\hline Base & 94.15 & 112.04 & 11.05 \\
Center & 87.92 & 111.90 & 11.05 \\
Top & 91.90 & 106.47 & 10.34 \\
$\begin{array}{c}\text { Average } \\
\text { Standard } \\
\text { deviation }\end{array}$ & 91.32 & 110.14 & 10.81 \\
$\begin{array}{c}\text { Variation } \\
\text { coefficient }(\%)\end{array}$ & 31.49 & 37.02 & 0.98 \\
\hline
\end{tabular}




\section{Interlaminar shear strength parallel to the fibers}

Table 7 lists the shear strength parallel to the fibers of specimens with MC from $10 \%$ to $11 \%$. As expected, the presence of nodes improved the shear strength. At this point, the fibers were not parallel; hence, they created a zone that is more resistant to shear.

Cantos et al. (2019) reported higher values for Bambusa blumeana. This difference can be attributed to the geometry of the specimen and the type of apparatus employed.

TABLE 7. Shear strength parallel to the fibers of B. vulgaris.

\begin{tabular}{cccc}
\hline \multicolumn{4}{c}{ Interlaminar shear strength parallel to the fibers } \\
\hline Culm Part & $\begin{array}{c}\text { With node } \\
(\mathbf{M P a})\end{array}$ & $\begin{array}{c}\text { Without } \\
\text { node (MPa) }\end{array}$ & $\begin{array}{c}\text { Moisture } \\
\text { content (\%) }\end{array}$ \\
\hline Base & 5.58 & 4.88 & 11.05 \\
Center & 6.68 & 4.38 & 11.05 \\
Top & 6.96 & 4.05 & 10.34 \\
$\begin{array}{c}\text { Average } \\
\text { Standard } \\
\text { deviation }\end{array}$ & 6.41 & 4.44 & 10.81 \\
$\begin{array}{c}\text { Variation } \\
\text { coefficient (\%) }\end{array}$ & 31.10 & 26.43 & 0.98 \\
\hline
\end{tabular}

\section{CONCLUSIONS}

The dimensional variations confirmed that, for bamboo species, shrinkage along the direction parallel to the fibers is considerably smaller than in the other directions. The thickness of the bamboo wall can increase by $5 \%$ when immersed in water.

The specific weight of the pole wall ranged from 8.5 $\mathrm{kN} / \mathrm{m}^{3}$ to $9.0 \mathrm{kN} / \mathrm{m}^{3}$.

The external diameter of the culm is approximately $6 \mathrm{~cm}$ in the basal and median zone and decreases in the apical region. The minimum and maximum values are $3 \mathrm{~cm}$ and $7 \mathrm{~cm}$, respectively.

The behavior of the external diameter differs from other species, in which the diameter continuously decreases along the height. The diameter of the B. vulgaris species is almost the same at the base and middle parts of the pole.

The internode length tends to be higher in the median area compared with other species. The values ranged from $20 \mathrm{~cm}$ (basal zone) to $47 \mathrm{~cm}$ (middle zone).

The wall thickness of $B$. vulgaris and that of most species decreased from base to top. The minimum and maximum values were $4 \mathrm{~mm}$ and $18 \mathrm{~mm}$, respectively.

The average compressive strength parallel to the fibers of B. vulgaris was approximately $64 \mathrm{MPa}$, with a variation coefficient of $28 \%(\mathrm{MC}=7 \%)$. Specimens with a node had lower strength compared with those without a node.

The average tensile strength parallel to the fibers of B. vulgaris with a node was approximately $91 \mathrm{MPa}$, with a variation coefficient of $31.5 \%(\mathrm{MC}=11 \%)$. For specimens without a node, the tensile strength increased to $110 \mathrm{MPa}$.
The average shear strength parallel to the fibers of $B$. vulgaris for specimens with a node was $6.4 \mathrm{MPa}$ with a variation coefficient of $31.1 \%(\mathrm{MC}=11 \%)$. For specimens without a node, the shear strength decreased to $4.4 \mathrm{MPa}$.

Despite the high coefficients of variation of the tests, $B$. vulgaris has properties similar to other species and is suitable for applications in architecture and engineering.

\section{ACKNOWLEDGMENTS}

The authors gratefully thank and dedicate this work to Prof. Dr. Antonio Ludovico Beraldo who passed away during this article edition. He left a huge contribution to the bamboo research in Brazil. Thank you professor Beraldo, we will miss you.

\section{REFERENCES}

Awalluddin D, Ariffin MAM, Osman MH, Hussin MW, Ismail MA, Lee H, Lim NHAS (2017) Mechanical properties of different bamboo species. In: MATEC Web of Conferences. South Korea, 138. EACEF. DOI: http://dx.doi.org/10.1051/matecconf/201713801024

Bhonde D, Nagarnaik PB, Parbat DK, Waghe UP (2014)

Physical and mechanical properties of bamboo

(Dendrocalamus strictus). International Journal of Scientific and Engineering Research. 5(1):455-459.

Cantos GL, Lopez LF, Jesus RM, Salzer C, Garciano L (2019) Investigation of an alternative testing protocol to determine the shear strength of bamboo parallel to the grain. Maderas. Ciencia y Tecnología 21(4): 559-564. DOI: http://dx.doi.org/10.4067/S0718221X2019005000411

Carbonari G, Silva Junior N, Pedrosa NH, Abe CH, Scholtz MF, Acosta CCV, Carbonari LT (2017) Bambu O aço vegetal. Mix Sustentável. 3(1):17-25. DOI: http://dx.doi.org/10.29183/2447-3073.MIX2017.v3.n1.17-25

Escamilla EZ, Habert G, Daza JFC, Archila HF, Fernández JSE, Trujillo D (2018) Industrial or traditional bamboo construction? Comparative life cycle assessment (LCA) of bamboo-based buildings. Sustainability 10(9): 3096. DOI: http://dx.doi.org/10.3390/su10093096.

Escamilla EZ, Habert G, Wohlmuth E (2016) When CO2 counts: Sustainability assessment of industrialized bamboo as an alternative for social housing programs in the Philippines. Building and Environment 103: 44-53.

Espitia M, Sjogreen C, Rodríguez N, Calderón J, Benavides A, Peraza R, Espitia G, Nemocon R (2018) Mechanical and physical characterization of Guadua angustifolia "Kunth" fibers from Colombia. Revista UIS Ingenierías 17(2): 33-40.

Ghavami K, Barbosa NP (2017) Bambu. In: Materiais de construção civil. IBRACON 48(2): 1566-1592. 
Ghavami K, García J J (2017) Four decades of research means building with bamboo comes of age. Proceedings of the Institution of Civil Engineers - Civil Engineering. 170(3): 101-101. DOI:

http://dx.doi.org/10.1680/jcien.2017.170.3.101.

Ghavami K, Marinho AB (2003) Propriedades geométricas e mecânicas de colmos dos Bambus para aplicação em construções. Revista de Engenharia e Agricultura 23(3): 415-424.

Ghavami K (2005) Bamboo as reinforcement in structural concrete elements. Cement and Concrete Composites 27(6): 637-649.

ISO - International Organization for Standardization (2004) ISO 22157: Determination of Physical and Mechanical Properties of Bamboo - Part 1: Requirements. ISO.

Jakovljević S, Lisjak D (2019) Investigation into the effects of humidity on the mechanical and physical properties of bamboo. Construction and Building Materials 194: 386-396.
Liese W, Kohl M (2015) Bamboo - the plant and its uses. Springer International Publishing, v1, 356p. DOI: http://dx.doi.org/10.1007/978-3-319-14133-6.

Mehta P K, Monteiro P J M (2014) Concreto: microestrutura, propriedades e materiais. IBRACON, 2 ed. $674 \mathrm{p}$.

Takeuchi CP, Estrada M, Linero DL (2018) Experimental and numerical modeling of shear behavior of laminated Guadua bamboo for different fiber directions. Construction and Building Materials 177: 23-32.

Xu Q, Harries K, Li X, Liu Q, Gottron J (2014) Mechanical properties of structural bamboo following immersion in water. Engineering Structures 81: 230-239.

Song J, Utama Surjadi J, Hu D, Lu Y (2017) Fatigue characterization of structural bamboo materials under flexural bending. International Journal of Fatigue. 100: 126-135. 